\title{
The Optimality of the Common Fisheries Policy: the Northern Stock of Hake ${ }^{\dagger}$
}

\author{
José-María Da-Rocha ${ }^{1}$, María-José Gutiérrez ${ }^{2}$ \\ 1 Departamento de Economía. Universidad Carlos III de Madrid and RGEA-Universidade de Vigo. \\ C/ Madrid 126, 28903 Getafe, Madrid. e-mail: jrocha@eco.uc3m.es \\ 2 DFAE II - University of the Basque Country. \\ Avda. Lehendakari Aguirre, 83, 48015 Bilbao. e-mail: jepguhum@bs.ehu.es
}

April 2004

\begin{abstract}
We evaluate the management of the Northern Stock of Hake during 1986-2001. A stochastic bioeconomic model is calibrated to match the main features of this fishing ground. We show how catches, biomass stock and profits would have been if the optimal Common Fisheries Policy (CFP) consistent with the target biomass implied by the Fischler's Recovery Plan had been implemented. The main finding are: i) an optimal CFP would have generated profits of more than 667 millions euros, ii) if side-payments are allowed (implemented by ITQ's, for example) these profits increase $26 \%$.
\end{abstract}

JEL Classification: Q22, Q28.

Key words: Common Fisheries Policy, Fishing Regulation, Fischler Recovery Plan.

Short running title: The Optimality of the CFP.

\footnotetext{
† We thank two anonymous referees whose comments and suggestions have substantially improved the paper, and to Javier Pereiro from Instituto Oceanográfico de Vigo for making available part of data available to us. Financial support from the Instituto de Estudios Económicos de Galicia, Pedro Barrie de la Maza, FEDER, Ministerio de Ciencia y Tecnología, SEC2002-4318-C02-01 (José María Da-Rocha), CICYT 1393-12254/2000 and SEC200302510/ECO (María José Gutiérrez), Fundación BBVA 1/BBVA 00044.321-15466/2002 (María José Gutiérrez) and from Universidad del País Vasco, 9/UPV00035.321-13511/2001 (María José Gutiérrez) is gratefully acknowledged.
} 


\section{Introduction}

The total allowable catch (TAC) is the key element in the management of fishing exploitation rates considered by the Common Fisheries Policy (CFP). At the end of each year, on the basis of scientific advice given mainly by the ICES (International Council for the Exploration of the Sea), the Council of Ministers sets the TACs for certain important species of fishes. Each TAC is divided up among the member states in the form of quotas according to the Relative Stability Principle (RSP). Most of the quotas were set for the first time in 1983. In establishing them the Council took into account the traditional fishing activities of each country and the specific needs of the regions particularly dependent on the fishery sector ("Hague Preferences"). The distribution settled in 1983 was modified in 1986 after the accession of Spain and Portugal to the European Community.

In general terms, the CFP failed to manage efficiently the fishing grounds. The Commission recognizes "[...] the alarming state of many fish stocks that are outside safe biological limits. Stock sizes and landings have declined dramatically over the last 25 years. For many commercially important demersal stocks, the numbers of mature fish were about twice as high in the early 1970's than in the late 1990's. It current trends continue many Community fish stocks will collapse". ${ }^{1}$ Given this situation, a new regulation of the CFP come into force on January 1st, $2003 .^{2}$

The objective of this paper is to quantify the losses associated with the exploitation of the CFP in regard to the Northern Stock of Hake from 1986 to 2001. This is a common fishing ground regulated by the CFP which is formed mainly by ICES zones VII and VIII ${ }^{3}$ and is exploited by the Spanish and French fleets. Biomass in this fishing ground dropped from about 290,000 Tn. in the early 1980 s to $170,000 \mathrm{Tn}$. in 2001 . This reduction was reflected in captures, which dropped from 60,000 Tn. to 37,000 Tn. in the same period. In October 2001, the ICES Advisory Committee for Fisheries Management considered that the stock was outside safe biological limits. In the light of ICES recommendations, Commissioner Fischler presented an Emergency Plan to recover the Northern Stock of Hake. ${ }^{4}$

European hake (merluccius merluccius) has also been studied from the economic point of view by other authors. For instance, Garza-Gil (1998) illustrates how individual transferable quotas may help to achieve efficient exploitation in a multifleet setting using data from the Southern Stock of Hake. ${ }^{5}$ However our paper addresses the problem of efficient exploitation in a different manner

\footnotetext{
${ }^{1}$ Roadmap 2002, page 3 .

${ }^{2}$ Council Regulation (EC) No 2371/2002.

${ }^{3}$ The Northern Stock of Hake is formed by ICES areas IIa, IIIa,b,c,d, IV, Vb, VI, VII and VIIIa,b,d,e. However captures from areas VII and VIII represent more than $90 \%$ of total captures of the whole stock.

${ }^{4}$ The proposal for the Recovery Plan was presented in June 2001 (COM(2001) 326 final), and in December 2002 was amended $(\mathrm{COM}(2002) 773$ final).

${ }^{5}$ The Southern Stock of Hake is formed by areas VIIIc and IXa which correspond to the east Portuguese waters and the south of the Bay of Biscay. ICES divides the Atlantic stock of hake in the Northern and the Southern stock for managerial purpouses. However authors as Roldan et al. (1998) point out that the population genetic structure
} 
than in Garza- Gil (1998). While she considers exploitation in the steady state, we analyze the transition from the initial situation to the steady state in the presence of productivity shocks.

We build an stochastic model for a heterogeneous multi fleet fishery regulated by a common policymaker in order to show how to define an Optimal Common Fisheries Policy (OCFP). This stochastic bioeconomic model is calibrated in order to reproduce the main characteristics of the observed exploitation of the Northern Stock of Hake from 1986 to 2001: the relative catches per unit of effort (c.p.u.e.) of the French and Spanish fleets; the observed catches and biomass stock of the Northern Stock of Hake during the period 1978-2000 and the quotas associated with the RSP obtained from the national TAC's established by the CFP during 1986-2001. Moreover the calibration is consistent with the target stock implied by the Fischler recovery plan approved in the Council Meetings held in December 2001 and June 2002 with the aim of recovering the stock of Hake.

The calibrated model is used to show how catches, biomass stock and profits would have been if the OCFP had been implemented and what would have happened if side-payments had been allowed. The main finding is that an OCFP would have generated more than 111,698 Tn. of profits and a policy that allowed for side-payments (implemented by individual transferable quotas (ITQ), for example) would have increased these profits by $26 \%$.

The paper proceeds as follows. In the next section we build the model and an OCFP is defined. The model is adapted to characterize the Northern Stock of Hake in Section 3. Subsection 3.1 presents the deterministic steady state version of the model which is useful for the calibration part of the paper. In Subsection 3.2 the calibration of the fishery is illustrated. Section 4 reports the quantitative experiments: first, how efficient the CFP was during the period studied; second, what would have happened if side-payments between fleets had been allowed. Section 5 concludes.

\section{The Model}

In order to show how we define an OCFP we build a model for a heterogeneous multi fleet fishery regulated by a common policymaker. Assume that the dynamics of the aggregate level of catches in period $t, Y_{t}\left(L_{t}, X_{t}\right)$, depend upon the total effective effort, $L_{t}$, and the level of fish stock in this period, $X_{t}$. To introduce heterogeneity we make two assumptions. First, we assume that the effective effort of each fleet is a function of its productivity, in particular we define the effective effort of country $i$ as $l_{i}^{\theta_{i}}$ where $\theta_{i}$ represents the productivity parameter of fleet $i$. Therefore, the total effort of the fishery can be expressed as

$$
L_{t}=\sum_{k=1}^{n} l_{k, t}^{\theta_{k}},
$$

of the hake is more complex than the discrete Northern and Southern stock proposed by ICES. 
where $n$ is the number of fleets fishing in the area. Second, each country $i$ obtains a share of the total catches, a quota $s_{i, t}$, which is proportional to its share in the total effective effort. Formally,

$$
s_{i, t}=\frac{y_{i, t}}{Y_{t}}=\frac{l_{i, t}^{\theta_{i}}}{L_{t}}, \quad \forall i=1, \ldots, n .
$$

These two assumptions allow us to express the production function of each country as a function of its own effort and that of the rest of the fleets, i.e. for each country $i=1, \ldots, n$,

$$
y_{i, t}\left(l_{1, t}, \ldots, l_{n, t}, X_{t}\right)=\frac{l_{i, t}^{\theta_{i}}}{\sum_{k=1}^{n} l_{k, t}^{\theta_{k}}} Y_{t}\left(L_{t}, X_{t}\right), \quad \forall i=1, \ldots, n .
$$

Notice that this expression implies two different externality effects of the effort of one of the fleets over the captures of the other fleets. On the one hand a raise of the current effort of any fleet produces an increase in total current captures and this reduces future stock and therefore future individual captures. So this intertemporal effect is negative provided $\partial Y_{t} / \partial X_{t}>0$. On the other hand an increase in the effort of fleet $j$ reduces the quota of any fleet $i \neq j$ but at the same time increase total captures. This is an intratemporal effect which is ambiguous whenever $\partial Y_{t} / \partial L_{t}>0{ }^{6}$

Finally the dynamic of the biomass is given by

$$
X_{t+1}=F\left(X_{t}\right)-Y_{t}
$$

where $F\left(X_{t}\right)$ is the gross growth of the biomass which is called the stock-recruitment relation and, following the terminology of fishery biologists, $X_{t+1}$ can be called the escapement ${ }^{7}$. We assume that $F\left(X_{t}\right)$ is a continuously, twice differentiable and strictly concave function.

Let us suppose that the common fishery is managed by a benevolent regulator who maximizes the expected present discount value of the weighted future profits of the fleets,

$$
E_{0} \sum_{t=0}^{\infty} \beta^{t}\left(\gamma_{1} \Pi_{1, t}+\gamma_{2} \Pi_{2, t}+\ldots+\gamma_{n} \Pi_{n, t}\right),
$$

where $E_{t}$ represents the expectation taken at time $t$ and $\beta$ is the discount factor. $\Pi_{i, t}$ represents the profit of fleet $i$ in period $t$, defined as the difference between its catches, $y_{i, t}$, and the real effort cost (measured in units of fish), $\omega_{i} l_{i, t} \cdot \gamma_{i}$ is the exogenous weight of country $i$ in the regulator's objective function. These weights can be interpreted as the political power of country $i$ within the regulatory agency. A similar interpretation for the case of international environmental agreements can be found in Escapa and Gutiérrez (1997). ${ }^{8}$

\footnotetext{
${ }^{6}$ This assumption implies that, at any time, captures by one fleet depend on the effort of the other fleets. We consider that this is an acceptable approach in an aggregate analysis of the fleets but it may be difficult to approve in a micro-level study. In any case, we are aware that this model includes an extra externality that may overestimate the welfare gains from cooperation.

${ }^{7}$ See Clark (1990, Ch. 7) for a study of the discrete-time and metered models of fisheries.

${ }^{8}$ The need to introduce of political elements into fishery regulation was acknowledged by Emma Bonino, exCommissioner for Fisheries (see point 4 in the Memorandum on Questions raised by the preparation of the MAGP IV, 1997).
} 
An optimal policy for managing the resource, OCFP, is a path for stock and efforts $\left\{X_{t+1},\left\{l_{i, t}\right\}_{i=1}^{n}\right\}_{t=0}^{\infty}$ that solves the following problem:

$$
[O C F P] \equiv\left\{\begin{array}{l}
\max _{\left\{X_{t+1},\left\{l_{i, t}\right\}_{i=1}^{n}\right\}_{t=0}^{\infty}} E_{0} \sum_{t=0}^{\infty} \beta^{t}\left(\gamma_{1} \Pi_{1, t}+\gamma_{2} \Pi_{2, t}+\ldots+\gamma_{n} \Pi_{n, t}\right), \\
\text { s.t. }\left\{\begin{array}{l}
\Pi_{i, t}=y_{i, t}\left(l_{1, t}, \ldots, l_{n, t}, X_{t}\right)-\omega l_{i, t}, \\
y_{i, t}\left(l_{1, t}, \ldots, l_{n, t}, X_{t}\right)=\frac{l_{i, t}^{\theta_{2}}}{\sum_{k=1}^{n} l_{k, t}^{\theta_{k}}} Y\left(L_{t}, X_{t}\right), \\
X_{t+1}=F\left(X_{t}\right)-\sum_{i=1}^{n} y_{i, t}\left(l_{1, t}, \ldots, l_{n, t}, X_{t}\right), \\
L_{t}=\sum_{i=1}^{n} l_{i, t}^{\theta_{i}} .
\end{array}\right.
\end{array}\right.
$$

The solution of this problem is a vector of effort $\left\{l_{i, t}^{*}\right\}_{i=1}^{n}$, and stock target $X_{t+1}$, such that, for each period $t$ :

1. Given the current stock, $X_{t}$, total catches will be $Y_{t}\left(\sum_{i=1}^{n}\left(l_{i, t}^{*}\right)^{\theta_{i}}, X_{t}\right)$.

2. In the next period, $t+1$, the stock target is sustainable. That is: $X_{t+1}=F\left(X_{t}\right)-$ $Y_{t}\left(\sum_{i=1}^{n}\left(l_{i, t}^{*}\right)^{\theta_{i}}, X_{t}\right)$.

The solution of the regulator's problem can be written in terms of quotas. Let us define $L_{t}^{*}\left(\gamma_{1}, \ldots, \gamma_{n}, X_{t}\right)=\sum_{k=1}^{n}\left(l_{k, t}^{*}\right)^{\theta_{k}}\left(\gamma_{1}, \ldots, \gamma_{n}, X_{t}\right)$. Then the optimal quotas are given by

$$
s_{i, t}^{*}=\frac{l_{i, t}^{* \theta_{i}}}{L_{t}^{*}\left(\gamma_{1}, \ldots, \gamma_{n}, X_{t}\right)}, \quad \forall i=1, \ldots, n .
$$

This means that different sets of weights in the regulator's objective function imply different quotas for the fleets. In other words, the system of quotas associated with the RSP can be understood as an efficient policy under a particular set of weights. ${ }^{9}$

\section{The Northern Stock of Hake}

Hake has been the main species supporting trawling fleets off the Atlantic coasts of France and Spain since the 1930s, and it is present in the catches of nearly all fisheries in sub-areas ICES VII and VIII. In 2000, Spain took $61 \%$ of the catches, France $22 \%$, the UK about $6 \%$ and Ireland $4 \% .{ }^{10}$ Hake is caught throughout the year, though the peak landings are made in the spring-summer months. The three main gear types used by vessels fishing for hake as a target species are lines (Spain), fixed-nets and other trawls (all countries). Hake spawn from March to July at depths of

\footnotetext{
${ }^{9}$ See Da Rocha and Gutiérrez (2003) for an analysis of this issue in a deterministic context.

${ }^{10}$ Data from Table 5.1.1. in Report ICES CM 2002/ACFM:05.
} 
120-160 m., mainly to the south and west of Ireland. They move to shallower water by September. The two major nursery areas are the Bay of Biscay and off southern Ireland. As they become mature, they disperse to offshore regions of the Bay of Biscay and Celtic Sea. Male hake mature at 3-4 years old $(27-35 \mathrm{~cm})$ and females at 5-7 years old $(50-70 \mathrm{~cm})$.

Like all the main stocks of the EU, the Northern Stock of Hake is managed by TAC and quotas with associated technical measures. During the period analyzed the Commission allocated an average of $55 \%$ of the TAC to France, $30 \%$ to Spain, $11 \%$ to the UK and $3 \%$ to Ireland (see Da Rocha and Gutiérrez (2003)). The minimum legal sizes for fish caught in this area is $27 \mathrm{~cm}$ total length.

Biomass dropped from about 290,000 Tn. in the early 1980s to 170,000 Tn. in 2001 (see Table 6 in Appendix A.2). This reduction was reflected in captures, which dropped from 60,000 Tn. to 37,000 Tn. in the same period. In October 2000, the ICES Advisory Committee for Fisheries Management considered that the stock was outside safe biological limits. In the light of ICES recommendations, an Emergency Plan was implemented by the Commission in June 2001 to recover the Northern Stock of Hake. The objective is to reduce catches of small hake in fisheries taking place in hake nursery areas. Nevertheless, these emergency measures do not apply to vessels less than $12 \mathrm{~m}$ in length which return to port within 24 hours of their most recent departure (Council Regulations 1162/2001, 2602/2001 and 494/2002). For more detailed information see the last report drawn up by the Working Group on the Assessment of Southern Stocks of Hake, Monk and Megrim (WGHMM) (Report ICES CM 2003/ACMF:01).

\subsection{Characterization of the Steady State}

To analyze the optimality of the CFP in the Northern Stock of Hake, we use a dynamic stochastic version of Spence's model (1974) for the case of a heterogeneous multi fleet fishery. ${ }^{11}$ The total catches function is given by

$$
Y_{t}=\left[1-e^{-\lambda L_{t}}\right] F\left(X_{t}\right)
$$

where $\lambda$ is a capturability parameter.

The stock-recruitment relation is a Cushing function, i.e.

$$
F\left(X_{t}\right)=A_{t} X_{t}^{\alpha}
$$

where parameter $\alpha$ represents the elasticity of the gross stock growth and $A_{t}$ is a random variable that can be interpreted as the productivity of the resource at time $t$, which can change as a function

\footnotetext{
${ }^{11}$ Spence (1974) developed a deterministic model in order to analyze Antarctic whale harvesting. It has also been used by other authors such as Gallastegui (1983) for the sardine fishery of the Gulf of Valencia (Spain) and Amundsen et al. (1995) for the Northeast Atlantic Minke Whale.
} 
of the state of nature. ${ }^{12}$ We assume that $A_{t}=e^{z_{t}} A$, where $A$ is a constant and $z_{t}$ is a random variable with mean zero which follows a Markov process, with a transition matrix, $\pi$.

Considering the capturability function, (1), and the gross growth of the biomass, (2), the steady state, without uncertainty, of the resource associated with the OCFP is given by (see Appendix A.1):

$$
\begin{gathered}
\left(\alpha \beta A X^{\alpha-1}-1\right) \sum_{i=1}^{n} \gamma_{i} \frac{l_{i}^{\theta_{i}}}{L}+\frac{(1-\alpha \beta) \omega}{\lambda X L} \sum_{i=1}^{n} \gamma_{i} \frac{l_{i}}{\theta_{i}}=0, \\
X=\left(e^{-\lambda L} A\right)^{\frac{1}{1-\alpha}}, \\
\frac{\left[\omega L / \theta_{i} l_{i}^{\theta_{i}-1}\right]-\left[A X^{\alpha}-X\right]}{\left[\omega L / \theta_{k} l_{k}^{\theta_{k}-1}\right]-\left[A X^{\alpha}-X\right]}=\frac{\gamma_{k}}{\gamma_{i}}, \quad \forall k \neq i,
\end{gathered}
$$

where $L=\sum_{i=1}^{n} l_{i}^{\theta_{i}}$. We can interpret the solution in the following way: equations (3) and (4) determine the level of stock and total effort that are compatible, and equation (5) indicates how effort should be shared out among the national fleets.

We can express the steady state as a function of the observed data, the quotas $\hat{s}_{i}$, the TAC, $Y$, and the biomass stock, $X$, using that $l_{i}=\left(s_{i} L\right)^{1 / \theta_{i}}$,

$$
\begin{gathered}
\left(\alpha \beta A X^{\alpha-1}-1\right) \sum_{i=1}^{n} \gamma_{i} s_{i}+\frac{(1-\alpha \beta) \omega}{\lambda X L(X)} \sum_{i=1}^{n} \gamma_{i} \frac{\left(s_{i} L(X)\right)^{1 / \theta_{i}}}{\theta_{i}}=0 \\
A X^{\alpha}-X=Y \\
\frac{\left[\omega L(X)^{1 / \theta_{i}} s_{i}^{\left(1-\theta_{i}\right) / \theta_{i}} / \theta_{i}\right]-Y}{\left[\omega L(X)^{1 / \theta_{k}} s_{k}^{\left(1-\theta_{k}\right) / \theta_{k}} / \theta_{k}\right]-Y}=\frac{\gamma_{k}}{\gamma_{i}}, \quad \forall k \neq i
\end{gathered}
$$

where $L(X)=(-1 / \lambda) \ln \left(X^{1-\alpha} / A\right)$ and $\sum_{i=1}^{n} s_{i}=1$. These equations are useful for our calibration strategy in the next section.

\subsection{Calibration}

We calibrate the model assuming that three fleets operate in the Northern Stock of Hake: Spain, France and the Rest of the Union. We denote their variables with the subscripts $s p, f r$ and $r u$,

\footnotetext{
${ }^{12}$ Other authors have introduced uncertainty into the dynamics of the resource. For instance, Danielsson (2002) and Weitzman (2002) analyze the relative performance of different methods of fisheries management when there are some risks involved. Androkovich and Stolley (1989) simulated a stochastic dynamic program where the growth equation for the fish stock is aproximated by a linear function which can be hit by additive random disturbances.
} 
respectively. In this context, the model has thirteen parameters, $\alpha, A, z, \pi, \theta_{s p}, \theta_{f r}, \theta_{r u}, \lambda, \gamma_{s p}$, $\gamma_{f r}, \gamma_{r u}, \omega$ and $\beta$. The model is calibrated to reproduce: (1) relative catches per unit of effort (c.p.u.e) of the French and Spanish fleets in areas VII and VIII; (2) catches and biomass stock of the Northern Stock of Hake during the period 1978-2001; (3) quotas obtained from the average TAC's during the period 1986-2002; and (4) the target stock announced by Fischler's recovery plan.

The parameters from the biological resource equation, $\alpha, A, z$ and $\pi$ can be calibrated with available data on stock and total captures. Calibration of biological resource equation parameters is based on available data for stock and total captures from the period 1978-2001 in the Northern Stock of Hake. These data were compiled by the Working Group on the Assessment of Southern Stocks of Hake, Monk and Megrim (WGHMM) from the ICES and are shown in Table 6 in Appendix A.2. The first step in calibration consists of estimating $A$ and $\alpha$ from the biological equation expressed in logarithms,

$$
\log \left(X_{t+1}+Y_{t}\right)=\log A+\alpha \log X_{t}+z_{t}
$$

The results of estimation by OLS imply $\hat{A}=12.8519$ and $\hat{\alpha}=0.8095$. Both estimates are significantly different from zero ( $t$ statistics are 2.737856 and 10.683081 for $A$ and $\alpha$, respectively) and $R^{2}=0.845$. Other alternative functional forms for the dynamic resource equation, apart from Cushing, have been considered. Table 9 in Appendix A.3 shows the estimation results for the logistic, logistic with minimum viable size, Ricker and Gompertz functions.

From the estimated errors,

$$
\hat{z}_{t}=\log \left(\frac{X_{t+1}+Y_{t}}{\hat{A} X_{t}^{\hat{\alpha}}}\right),
$$

we estimate an $\operatorname{AR}(1)$ process $\hat{z}_{t+1}=\rho \hat{z}_{t}+\varepsilon_{\hat{z}}$, obtaining an estimated autoregressive coefficient $\hat{\rho}=-0.11741$. Once those parameters have been estimated, the stochastic process is calibrated in such a way that the sequence of productivity shocks reproduces the stock and total catches observed from 1978 to 2001. In order to do this, we have taken five equidistant values for the state of the productivity shock, that is $z \in\{-0.1510,-0.0755,0,0.0755,0.1510\}$. Figures 1 and 2 show the observed and calibrated productivity shocks and stocks, respectively, from 1978 on.

\section{[Figure 1 about here]}

\section{[Figure 2 about here]}

Given $\hat{\rho}$ and the values for the states of $z$, we calculate the transition matrix, $\pi$, for the Markov chain that discrete a continuum process in five states (see Tauchen (1986)). The calibrated 
values are

$$
\pi\left(z, z^{\prime}\right)=\left(\begin{array}{lllll}
0.0006 & 0.1991 & 0.5221 & 0.3164 & 0.0318 \\
0.0035 & 0.1682 & 0.5428 & 0.2633 & 0.0222 \\
0.0080 & 0.2133 & 0.5499 & 0.2133 & 0.0155 \\
0.0146 & 0.2633 & 0.5428 & 0.1682 & 0.0111 \\
0.0242 & 0.3164 & 0.5221 & 0.1291 & 0.0082
\end{array}\right),
$$

where $\pi_{j, i}=\operatorname{Pr}\left[z_{t+1}=z_{j} \mid z_{t}=z_{i}\right]$.

To calibrate the productivity parameters, $\theta_{s p}$ and $\theta_{f r}$, and the capturability parameter, $\lambda$, we use a two-step procedure. First, we calibrate a parameter $\phi$ that reflects productivity differences between the Spanish and French trawler fleets using data from homogenous fleets. Second, $\theta_{f r}$ and $\lambda$ are calibrated to target the French data on effort and catches. We follow this two-step procedure because we do not have effort data for the whole Spanish fleet.

To calibrate $\phi$ reflecting the differences on productivities when homogeneous fleets are considered we assume that effort is independent of the productivity parameters. Under this assumption we can express the relationship between effort and shares for the Spanish and French fleets as

$$
\frac{s_{f r}}{s_{s p}}=\frac{l_{f r}^{\phi}}{l_{s p}} .
$$

In order to evaluate $\phi$, we use data on c.p.u.e. by fleets provided by the WGHMM of the ICES and captures by fleets from Instituto Oceanográfico de Vigo. In particular, the Spanish c.p.u.e. data correspond to the Coruña trawler fleet which operates in deeper waters close to the slope in division VIIb,c,j,k. The French c.p.u.e. data come from the FR-RESSGASCS survey conducted in the Bay of Biscay following French trawlers fishing in subarea VIIIa,b (see Table 7 in Appendix A.2). Effort data can be calculated as captures/c.p.u.e. Shares for the trawler fleets have been calculated as the ratio of captures of each fleet in the area in which the reference trawler fleet fishes to total captures of the Northern Stock. However, since data on captures by fleets are available only for the years 1988-1990, we can only calculate effort and share data by fleets for those years. The data drawn up are summarized in Table $1 .{ }^{13} \phi$ is calculated from equation (9) taking the average values in Table 1.

\section{[Table 1 about here]}

The capturability parameter, $\lambda$, and the productivity parameter for the French fleet, $\theta_{f r}$, are jointly calibrated to reproduce the effort and capture data of the French fleet in subareas VII and

\footnotetext{
${ }^{13}$ We thank Javier Pereiro fom Instituto Oceanográfico de Vigo for making data available to us.
} 
VIII of the Northern Stock. To do this we use the capturability equation (1) expressing the total effort in terms of the French share and effort, that is

$$
Y_{t}=\left[1-e^{-\lambda\left(l_{f r}^{\theta_{f r}} / s_{f r}\right)}\right] F\left(X_{t}\right)
$$

We have data for the whole French fleet as regard effort and captures in subareas VII and VIII for 1988-1990 (see Table 8 in Appendix A.2). ${ }^{14}$ Using these data, we have calculated $\lambda$ and $\theta_{f r}$ such that the squared error associated with the above equation is minimized for 1988-1990. The results are $\lambda=0.0061838352$ and $\theta_{f r}=0.49$. We assume that Spanish productivity is proportional to the differences observed in the trawler fleet, i.e. $\theta_{s p}=\theta_{f r} / \phi$. This implies $\theta_{s p}=0.53$. We also assume that the rest of the fleets that fish in the Northern Stock have the same productivity as the French fleet, that is $\theta_{r u}=\theta_{f r}$.

Finally, the weights in the regulator's objective function, $\gamma_{i}^{\prime} s$, and the real effort cost, $\omega$, are calibrated jointly to reproduce the legal TACs and the target stock proposed in the Fischler recovery plan. This plan was approved in the Council Meetings held in December 2001 and June 2002 with the aim of recovering the stock of hake (see, Documents 15383/1 and 9557/02). In particular, the objective is to introduce a multiannual recovery plan for hake with a recovery period of seven to eight years and yearly increases in the biomass of $15 \%$. Since the stock of hake in 2001 is 171,000 Tn. approximately, this multiannual plan will recover the stock up to around 450,000 Tn. We assume that a steady state situation will be reached when the stock has been recovered, i.e. when the stock reaches approximately 450,000 Tn.

As quotas for each fleet, we use the average of the legal quotas imposed by the CFP in areas VII and VIII during the period 1987-2002 adjusted to consider the whole Northern Stock of Hake. We know that the quotas imposed by the CFP in areas VII and VIII for this period are on average $s_{s p}=54.76 \%, s_{f r}=30.06 \%$, and $s_{r u}=15.18 \%$ (see Da Rocha and Gutiérrez (2003)). However areas VII and VIII only represent $93.72 \%$ of the captures in the Northern Stock of Hake. We also know that in 2000 captures outside areas VII and VIII were $9.52 \%$ for the Spanish fleet, $30.78 \%$ for the French fleet and $59.70 \%$ for the rest of the fleets (see Report ICES CM 2002, page 471). We have adjusted the data to obtain the quotas for the whole stock, i.e. $s_{s p}=51.92 \%, s_{f r}=30.10 \%$, and $s_{r u}=17.97 \%$.

With these data, the calibration of the other parameters, and the assumption that $\beta$ is 0.95 , we use (6), (7) and (8) to find the values of $\gamma_{s p}, \gamma_{f r}, \gamma_{r u}$ and $\omega$ that satisfy $\gamma_{s p}+\gamma_{f r}+\gamma_{r u}=1$.

The calibration results are summarized in Table 2. Observe that the maximum sustainable yield (MSY) in our biological model is given by $M S Y=\frac{1-\alpha}{\alpha}(\alpha A)^{1 /(1-\alpha)}$, which can be sustained

\footnotetext{
${ }^{14}$ Unfortunately, we do not have these data for the whole Spanish fleet, so we cannot jointly calibrate the parameters in the biological resource equation and capturability equation.
} 
with a biomass of $X_{M S Y}=(\alpha A)^{1 /(1-\alpha)}$. ${ }^{15}$ Given the calibration of parameters $\alpha$ and $A$, this implies $M S Y=51,444 \mathrm{Tn}$. The required biomass to maintain the MSY is $X_{M S Y}=218,610 \mathrm{Tn}$.

[Table 2 about here]

\section{Quantitative Experiments}

In this section we explore how efficient the CFP was in the Northern Stock of Hake from 1986 to 2001. In particular, we ask: i) How would catches, biomass stock and profits have been if the OCFP had been implemented? ii) What would have happened if the optimal policy with sidepayments had been implemented? The main findings in this section are: i) an OCFP would have generated more than 111, $000 \mathrm{Tn}$. of profits, which means more than 670 millions euros, considering 6 euros/kilo as the price of hake and ii) a policy that allowed for side-payments (implemented by ITQ's, for example) would have increased these profits by $26 \%$.

\subsection{The efficiency of the CFP}

In this section, we investigate whether the observed exploitation paths for 1986-2001 in the Northern Stock of Hake can be considered efficient given the quotas associated with the RSP, $\left\{\hat{s}_{i}\right\}_{i=1}^{n}$, and the initial conditions of the stock, $X_{0}=X_{1986}$. To simulate the model we iterate the value function associated with the OCFP problem. Given a system of quotas $\hat{s}$, the dynamic program can be expressed as a function of the stock, $X$, and the state of nature $z$. Formally, the value function is given by

$$
\begin{aligned}
V(z, X \mid \hat{s})=\max _{X^{\prime}} \sum_{i=1}^{n} \gamma_{i} \Pi_{i}\left(z, X, X^{\prime} \mid \hat{s}_{i}\right)+\beta E_{z^{\prime}}\left[V\left(z^{\prime}, X^{\prime} \mid \hat{s}\right) / z\right], \\
\text { s.t. }\left\{\begin{array}{l}
Y=A e^{z} X^{\alpha}-X^{\prime} \geq 0, \\
z \in\left[z_{1}, z_{2}, z_{3}, z_{4}, z_{5}\right], \pi,
\end{array}\right.
\end{aligned}
$$

where the profits of each fleet are given by

$$
\Pi_{i}\left(z, X, X^{\prime} \mid \hat{s}_{i}\right)=\hat{s}_{i} Y-\omega\left[-\frac{\hat{s}_{i}}{\lambda} \ln \left(\frac{X^{\prime}}{e^{z} A X^{\alpha}}\right)\right]^{1 / \theta_{i}} .
$$

\footnotetext{
${ }^{15}$ The $X_{M S Y}$ is the stock size such that the net growth of biomass is maximum. In other words, the value of $X$ for which $\partial\left(F\left(X_{t}\right)-X_{t}\right) / \partial X_{t}=0$. The $M S Y$ is the value of the net growth when $X=X_{M S Y}$. Recently, the National Marine Fisheries Service of the USA has started to call this "long-term potential yield".
} 
We calculate the OCFP using the calibrated parameters and simulate the optimal stock and catches paths associated with the stochastic shocks calibrated for the period 1986-2001. The results are illustrated in Figures 3 (a) and (b), respectively.

\section{[Figure 3 about here]}

We can see in Figure 3(a) that optimal exploitation led to a recovery of the stock until 1997, when it dropped again. Comparing this optimal path with the data we can conclude that the CFP has been a complete failure. In Figure 3 (b) we can observe that until 1996, captures were greater than they should have been according to optimal exploitation. In particular, in 1986 captures were about 60,000 Tn. when the optimal exploitation called for less than 10,000 Tn. The gap between the optimal and the observed catches was narrowed until 1997. However from then on this gap widened considerably. Therefore, the implementation of the CFP has been characterized by an excess of captures and effort that has depleted stocks and reduced profits. Table 3 shows the deviations of the observed exploitation paths from the optimal ones in aggregate terms. Captures are about $617,000 \mathrm{Tn}$. more than optimal. This means that effective exploitation has deviated by more than $260 \%$ from the efficient policy. This overexploitation has depleted stocks. In 2001 biomass was about 170,000 Tn. while optimal exploitation would require a resource stock of 462,000 Tn.

\section{[Table 3 about here]}

This overexploitation of the stock has dissipated profits. If the fleets had fished efficiently the present value of the future profits would have been 111,698 Tn. of resources, which means more than 670 million euros, considering 6 euros/kilo as the price of hake. Moreover, when the profits associated with the observed data for the whole period are calculated, considering the effort cost calibrated to match the target stock of the Commission, we observe that they are negative. This result is typical in open access fisheries. Therefore, we can assume that fleets are operating in fact in a situation of open access and profits are zero. This means that the inefficient exploitation of the Northern Stock of Hake has resulted in a monetary loss of more than 670 million euros.

\subsection{Optimal Side-Payments}

In this section we compare the OCFP associated with the quotas imposed by the Community according to the RSP with optimal exploitation in the case in which side-payments among fleets are allowed. Formally this solution is called the first optimum. It corresponds to the OCFP for the case in which the regulator does not discriminate between the fleets, that is when $\gamma_{i}=1 / n$. 
From the technical point of view, this solution could be implemented by the European Commission through a system of individual transferable quotas (ITQs). Observe that assigning a quota for catching a specified amount of fish to a fleet can lead to the first optimum provided this quota is transferable and divisible. In this case, each holder of the quota has a private property right to the fish and could sell or lease part or all of the quota to other fleets and receive the discounted future profit from the use of the quota. This may mean that over time an arbitrary distribution of quotas, for instance the quotas associated with RSP, should lead to the first optimum of effort and harvest.

Table 4 shows the quotas associated with OCFP as a result of side-payments between fleets. In other words, the Commission can share out the TAC among fleets a priori according to the RSP; however, if side-payments are allowed, then the TAC is shared out a posteriori, as Table 4 indicates. We can observe that the results imply a large redistribution of captures between countries. In particular there is a significant reduction of France's quota in favor of Spain and the Rest of the Union.

\section{[Table 4 about here]}

This result can also be observed in Figure 4, where capture paths for each of the policies considered are illustrated. Panel (a) shows that in aggregate terms the OCFP generates lower captures than the side-payments solution for all periods. The intuition for this result is clear; the side-payment solution is the optimal solution in which aggregate profits are maximized and it therefore allows more captures. However the redistribution of the TAC among fleets is uneven. We can observe in panels (b), (c) and (d) that the side-payments solution pushes France's captures below the OCFP policy level while those of Spain and Rest of the Union are above that level.

\section{[Figure 4 about here]}

Table 5 shows the results of the OCFP and side-payments policy in quantitative terms. Several points can be observed. First, if side-payments had been allowed, the stock would not have recovered as much as with the OCFP. In particular, the stock would be about 422,000 Tn. in 2001 . Second, with side-payments the capture path would have been less severe than that implied by the OCFP. Observed captures deviate by 504,000 Tn. from the side payments policy compared to $617,000 \mathrm{Tn}$. from the OCFP. And third, with side-payments the present value of total profits is $26 \%$ greater than under OCFP. Moreover, this increase in total profits is shared out differently among countries: Spain and the Rest of the Union increase their profits by $46 \%$ and $73 \%$, respectively, while France's profits drop by $14 \%$. Figure 5 compares the trends in stock and annual increase 
in profits under the OCFP and side-payments policies (panel (a) and (b) respectively). We can observe that the implementation of an optimal policy with side-payments generates greater profits year by year (the increase is more than $35 \%$ for some years). This rise in profits is due to a more efficient exploitation of the resource, which allows lower levels of stock to be maintained.

[Table 5 about here]

[Figure 5 about here]

\section{Conclusions}

In this paper we show how to define an optimal policy for a given quota. This allows us to define an optimal Common Fishery Policy (OCFP) where the optimal quotas are those associated with the Relative Stability Principle. We also show how to calibrate a model to reproduce the main facts of the exploitation in the Northern Stock of Hake from 1978 to 2001. Finally we use the calibrated model to simulate optimal catches, biomass of Hake and profits of each fleet. The main finding is that an OCFP would have generated more than 111,000 Tn. of profits (about 670 millions euro) and a policy that would have allowed side-payments would have increased the profits of the fishing ground by $26 \%$.

In future research we want to compute the profits from the stock recovery associated with the Fischler recovery plan. This will allow us to learn whether the profits associated with the recovery of the stock are greater than the cost of the destruction of effort associated with that proposal. 


\section{References}

[1] Amundsen, E.S., T. Bjorndal and J.M. Conrad (1995) Open Access Harvesting of the Northeast Atlantic Minke Whales. Environmental and Resource Economics 6, 167-185

[2] Androkovich, R.A. and K.R. Stollery (1989) Regulation of Stochastic Fisheries: A Comparison of Alternatives Methods in the Pacific Halibut Fishery. Marine Resource Economics 6, 109-22

[3] Bonino, E (1997) Memorandum on Questions Raised by the Preparation of the MAGP IV

[4] Clark, C.W. (1990) Mathematical Bioeconomics. The Optimal Management of Renewable Resources. John Wiley \& Sons (2nd ed.), New York, NY

[5] Conrad, J.M. (1999) Resource Economics. Cambridge University Press, Cambridge, MA

[6] Council Meeting 2400th OR(2001) of 17 December 2001 15383/01 (Presse 477-G)

[7] Council Meeting 2435th OR(2002) of 11 June 2002 9557/02 (Presse 172)

[8] Council Regulation $\operatorname{COM}(2001)$ 326,final of 12 June 2001 Communication from the Commission to the Council on the European Parliament on the Rebuilding Stocks of Cod and Hake in Community and Adjacent Waters

[9] Council Regulation $\operatorname{COM}(2002)$ 181,final of 28 May 2002 Communication from the Commission on the Reform of the Common Fisheries Policy ("Roadmap")

[10] Council Regulation COM(2002) 773,final of 20 December 2002 Amended Proposal for a Council Regulation on the Establishing Measures for the Recovery of Cod and Hake Stocks

[11] Council Regulation (EC) No 1162/2001 of 14 June 2001 on the Establishing Measures for the Recovery of the Stock of Hake in ICES sub-areas III, IV, V, VI and VII and ICES divisions VIIIa,b,d,e and Associated Conditions for the Control of Activities of Fishing Vessels

[12] Council Regulation (EC) No 2602/2001 of 27 December 2001 on the Establishing Additional Technical Measures for the Recovery of the Stock of Hake in ICES sub-areas III, IV, V, VI and VII and ICES divisions VIIIa,b,d,e

[13] Council Regulation (EC) No 494/2002 of 19 March 2002 on the Establishing Additional Technical Measures for the Recovery of the Stock of Hake in ICES sub-areas III, IV, V, VI and VII and ICES divisions VIIIa,b, d,e

[14] Council Regulation (EC) No 2371/2002 of 20 December 2002 on the Conservation and Sustainable Exploitation of Fisheries Resources under the Common Fisheries Policy. Official Journal of the European Communities

[15] Cox, D.R. and D.V. Hinkley (1980) Problems and Solutions in Theoretical Statistics. Chapman and Hall, London, UK 
[16] Da Rocha, J.M. and M.J. Gutiérrez (2003) La Reforma del Principio de Estabilidad Relativa en la Política Pesquera Común: El Caso del Caladero Norte de Merluza. Revista de Economía Aplicada, (forthcoming)

[17] Danielsson, A. (2002) Efficiency of Catch and Effort Quotas in the Presence of Risk.Journal of Environmental Economics and Management 43, 20-33

[18] Escapa, M. and M.J. Gutiérrez (1997) Distribution of Potential Gains from International Environmental Agreements: The Case of the Greenhouse Effect. Journal of Environmental Economics and Management 33, 1-16

[19] European Council Meeting (Fisheries), December 2001, Document 15383/01

[20] European Council Meeting (Fisheries), June 2002, Document 9557/02

[21] Hanley, N., Shogren, J.F. and B. White (1997) Environmental Economics: In Theory and Practice. MacMilan Press, London, UK

[22] Gallastegui, C. (1983) An Economic Analysis of Sardine Fishing in the Gulf of Valencia (Spain). Journal of Environmental Economics and Management 10, 138-50

[23] Garza-Gil, M.D. (1998) ITQ Systems in Multifleet Fisheries. An Application for Iberoatlantic Hake. Environmental and Resource Economics 11, 79-92

[24] ICES CM 2003/ACFM:01. Report of the Working Group on the Assessment of Southern Stocks of Hake, Monk and Megrim. Lisbon, Portugal. 21-30 May 2002

[25] ICES CM 2002/ACFM:05. Report elaborated by the Working Group on the Assessment of Southern Shelf Demersal Stocks. ICES Headquarters. 4-13 September 2001

[26] Roldán, M.I., J.L. García-Martín, F.M. Utter and C. Pla (1998) Population Genetic Structure of European Hake Merluccius Merluccius. Heredity 81(3), 327-334

[27] Spence, M. (1974) Blue Whales and Applied Control Theory. In: Zadeh, C.L. et al. (eds.) Systems Approaches for Solving Environmental Problems. Vandenhoeck and Ruprecht, Gottingen and Zurich

[28] Tauchen, G. (1986) Finite State Markov-Chain Approximations to Univariate and Vector Autoregresions. Economic Letters 20, 177-81

[29] Weitzman, M.L. (2002) Landing Fees vs Harvest Quotas with Uncertain Fish Stock. Journal of Environmental Economics and Management 43, 325-38. 


\section{A Appendix}

\section{A.1 Characterization of the Steady State}

The $[\mathrm{OCFP}]$ problem with functional forms in section 3 is:

$$
[O C F P] \equiv\left\{\begin{array}{cl}
\max _{\left\{\left\{l_{i, t}\right\}_{i=1}^{n}\right\}_{t=0}^{\infty}} E_{0} \sum_{t=0}^{\infty} \beta^{t}\left(\gamma_{1} \Pi_{1 t}+\gamma_{2} \Pi_{2 t}+\ldots+\gamma_{n} \Pi_{n t}\right) \\
\\
\text { s.t. } \quad \Pi_{i t}=y_{i, t}\left(l_{1, t}, \ldots, l_{n, t}, X_{t}\right)-\omega l_{i, t}, \\
& y_{i, t}\left(l_{1, t}, \ldots, l_{n, t}, X_{t}\right)=\frac{l_{i, t}^{\theta_{2}}}{\sum_{k=1}^{n} l_{k, t}^{\theta_{k}}}\left[1-e^{\left.-\lambda \sum_{k=1}^{n} l_{k, t}^{\theta_{k}}\right]} A_{t} X_{t}^{\alpha},\right. \\
& X_{t+1}=A_{t} X_{t}^{\alpha}-\sum_{i=1}^{n} y_{i, t}\left(l_{1, t}, \ldots, l_{n, t}, X_{t}\right) .
\end{array}\right.
$$

Since we are interested in characterizing the steady state without uncertainty, we remove the conditional expectation and consider $A_{t}=A$. The Lagrangian associated with this problem is

$$
L=\sum_{t=0}^{\infty} \beta^{t}\left\{\sum_{i=1}^{n} \gamma_{\imath}\left[y_{i, t}\left(l_{1, t}, \ldots, l_{n, t}, X_{t}\right)-\omega l_{i, t}\right]+\mu_{t}\left[A X_{t}^{\alpha}-\sum_{i=1}^{n} y_{i, t}\left(l_{1, t}, \ldots, l_{n, t}, X_{t}\right)-X_{t+1}\right]\right\},
$$

where $\mu_{t}$ is the multiplier. The f.o.c. of this problem are

$$
\begin{aligned}
\frac{\partial L}{\partial l_{i, t}} & =0 \Rightarrow \beta^{t}\left[\gamma_{2}\left(\frac{\partial y_{i, t}}{\partial l_{i, t}}-\omega\right)+\sum_{k \neq i} \gamma_{k} \frac{\partial y_{k, t}}{\partial l_{i, t}}-\mu_{t} \sum_{k=1}^{n} \frac{\partial y_{k, t}}{\partial l_{i, t}}\right]=0, \quad \forall i=1, \ldots, n \quad \forall t, \\
\frac{\partial L}{\partial X_{t+1}} & =0 \Rightarrow-\beta^{t} \mu_{t}+\beta^{t+1}\left[\sum_{i=1}^{n} \gamma_{2} \frac{\partial y_{i, t+1}}{\partial X_{t+1}}+\mu_{t+1}\left(A \alpha X_{t+1}^{\alpha-1}-\sum_{i=1}^{n} \frac{\partial y_{i, t+1}}{\partial X_{t+1}}\right)\right]=0, \quad \forall t, \\
\frac{\partial L}{\partial \mu_{t}} & =0 \Rightarrow X_{t+1}=X_{t}^{\alpha}-\sum_{i=1}^{n} y_{i, t}, \quad \forall t .
\end{aligned}
$$

We sketch the proof to transform these conditions into equations (6), (7) and (8). First, we find expressions for $\sum_{k=1}^{n}\left(\partial y_{k, t} / \partial l_{i, t}\right), \quad \sum_{k=1}^{n} \gamma_{k}\left(\partial y_{k, t} / \partial l_{i, t}\right), \quad \sum_{k=1}^{n}\left(\partial y_{k, t} / \partial X_{t}\right)$, and $\sum_{k=1}^{n} \gamma_{k}\left(\partial y_{k, t} / \partial X_{t}\right)$.

Given the definition of $y_{k, t}$ (second restriction in the OCFP problem), individual catches can be expressed as

$$
y_{k, t}=\frac{l_{k, t}^{\theta_{k}}}{\sum_{j=1}^{n} l_{j, t}^{\theta_{j}}}\left[1-e^{-\lambda \sum_{j=1}^{n} l_{j, t}^{\theta_{j}}}\right] A X_{t}^{\alpha}=s_{k, t}\left[1-e^{-\lambda \sum_{j=1}^{n} l_{j, t}^{\theta_{j}}}\right] A X_{t}^{\alpha},
$$

where $s_{k, t}=l_{k, t}^{\theta_{k}} / \sum_{j=1}^{n} l_{j, t}^{\theta_{j}}$.

It is easy to calculate $\forall i$,

$$
\begin{aligned}
\frac{\partial y_{k, t}}{\partial l_{i, t}} & =\left\{\left[1-e^{-\lambda \sum_{j=1}^{n} l_{j, t}^{\theta_{j}}}\right] \frac{\partial s_{k, t}}{\partial l_{i, t}}+\lambda \theta_{i} l_{i, t}^{\theta_{i}} e^{-\lambda \sum_{j=1}^{n} l_{j, t}^{\theta_{j}}} s_{k, t}\right\} A X_{t}^{\alpha}, \\
\frac{\partial y_{k, t}}{\partial X_{t}} & =\left[1-e^{-\lambda \sum_{j=1}^{n} l_{j, t}^{\theta_{j}}}\right] \alpha A X_{t}^{\alpha-1} s_{k, t},
\end{aligned}
$$

where

$$
\frac{\partial s_{k, t}}{\partial l_{i, t}}= \begin{cases}-\frac{\theta_{i}}{l_{i, t}} s_{i, t} s_{k, t} & \forall i \neq k \\ \frac{\theta_{i}}{l_{i, t}} s_{i, t}\left(1-s_{i, t}\right) & \forall i=k .\end{cases}
$$


Summing up (13) and (14) over $k=1, \ldots, n$ and taking into account that restrictions in the optimization problem imply, in the steady state, that $e^{-\lambda \sum_{j=1}^{n} l_{j, t}^{\theta_{j}}}=X^{1-\alpha} / A$, we can obtain the following expressions,

$$
\begin{aligned}
\sum_{k=1}^{n} \frac{\partial y_{k}}{\partial l_{i}} & =\lambda \frac{\theta_{i}}{l_{i}} l_{i}^{\theta_{i}} X, \\
\sum_{k=1}^{n} \gamma_{k} \frac{\partial y_{k}}{\partial l_{i}} & =\left\{\left[1-\frac{X^{1-\alpha}}{A}\right] s_{i}\left(\gamma_{i}-\sum_{k=1}^{n} \gamma_{k} s_{k}\right)+\lambda l_{i}^{\theta_{i}} \frac{X^{1-\alpha}}{A} \sum_{k=1}^{n} \gamma_{k} s_{k}\right\} \frac{\theta_{i}}{l_{i}} A X^{\alpha}, \\
\sum_{k=1}^{n} \frac{\partial y_{k}}{\partial X} & =\left[1-\frac{X^{1-\alpha}}{A}\right] \alpha A X^{\alpha-1}, \\
\sum_{k=1}^{n} \gamma_{k} \frac{\partial y_{k}}{\partial X} & =\left[1-\frac{X^{1-\alpha}}{A}\right] \alpha A X^{\alpha-1} \sum_{k=1}^{n} \gamma_{k} s_{k} .
\end{aligned}
$$

Substituting expressions (17) and (18) in optimality condition (11), this can be expressed in the steady state as

$$
\beta \alpha\left(A X^{\alpha-1}-1\right) \sum_{k=1}^{n} \gamma_{k} s_{k}-(1-\beta \alpha) \mu=0
$$

On the other hand, substituting expressions (15) and (16) in the optimality condition (10), we can express the multiplier $\mu_{t}$ in the steady state $\forall i=1, \ldots . n$, as

$$
\begin{aligned}
\mu & =\frac{\sum_{k=1}^{n} \gamma_{k} \frac{\partial y_{k}}{\partial l_{i}}-\gamma_{i} w}{\sum_{k=1}^{n} \frac{\partial y_{k}}{\partial l_{i}}} \\
& =\left\{\left[1-\frac{X^{1-\alpha}}{A}\right] s_{i}\left(\gamma_{i}-\sum_{k=1}^{n} \gamma_{k} s_{k}\right)+\lambda l_{i}^{\theta_{i}} \frac{X^{1-\alpha}}{A} \sum_{k=1}^{n} \gamma_{k} s_{k}\right\} \frac{A X^{\alpha-1}}{\lambda l_{i}^{\theta_{i}}}-\frac{\gamma_{i} w}{\lambda \theta_{i} l_{i}^{\theta_{i}-1} X} .
\end{aligned}
$$

Substituting this expression of $\mu$ in (19), and after some calculations, equation (6) in the main text is obtained.

To obtain equation (7) in the main text it suffices to equal $\mu$ for any two fleets and consider that $1-\frac{X^{1-\alpha}}{A}=\frac{Y}{A X^{\alpha}}$ and $L=l_{i}^{\theta_{i}} / s_{i}$.

\section{A.2 Data}

[Table 6 about here]

[Table 7 about here]

[Table 8 about here] 


\section{A.3 Estimates}

Table 9 shows the estimation of the dynamic resource equation using different functional forms. The two first blocks illustrates the results of estimation using the Cushing and the Ricker functions as stock-recruitment relation. The last three blocks show the estimations using the logistic, the logistic with minimum viable population size (MVPS) and the Gompertz as net growth biomass function. ${ }^{16}$. For a detailed description of these functions see Conrad (1999, pages 32-35) and Hanley et al. (1997, pages 276-280)

[Table 9 about here]

We can observe that the logistic with minimum viable population size (MVPS) function does not fit the data at all. Logistic, Gompertz and Ricker functions fit the data fairly well, however the Cushing function has been chosen because the parameters are both significantly different from zero with right signs and $R^{2}=0.845$.

For the reduced parameters, which are non linear combinations of the structural parameters, the $t$ statistic is calculated using as variance an approximation based on Taylor's expansion (see Cox and Hinkley 1980, page 105). For instance, assume that parameter $k=g\left(\beta_{1}, \beta_{2}\right)$, then

$$
\widehat{\sigma}_{K}^{2} \simeq\left[\frac{\partial g}{d \beta_{1}}\right]_{\left(\widehat{\beta}_{1}, \widehat{\beta}_{2}\right)}^{2} \widehat{\sigma}_{\beta_{1}}^{2}+\left[\frac{\partial g}{d \beta_{2}}\right]_{\left(\widehat{\beta}_{1}, \widehat{\beta}_{2}\right)}^{2} \widehat{\sigma}_{\beta_{2}}^{2}+\left[\frac{\partial g}{d \beta_{1}}\right]_{\left(\widehat{\beta}_{1}, \widehat{\beta}_{2}\right)}\left[\frac{\partial g}{d \beta_{2}}\right]_{\left(\widehat{\beta}_{1}, \widehat{\beta}_{2}\right)} \widehat{\operatorname{cov}}_{\beta_{1}, \beta_{1}}^{2},
$$

where $\widehat{\beta}_{1}$ and $\widehat{\beta}_{2}$ are unbiased estimators of the reduced parameters $\beta_{1}$ and $\beta_{2}$.

\footnotetext{
${ }^{16}$ Observe that given the net growth of the biomass, $G\left(X_{t}\right)$, the stock-recruitment relation (gross growth biomass function) is $F\left(X_{t}\right)=G\left(X_{t}\right)+X_{t}$.
} 
Figure 1: Productivity shocks

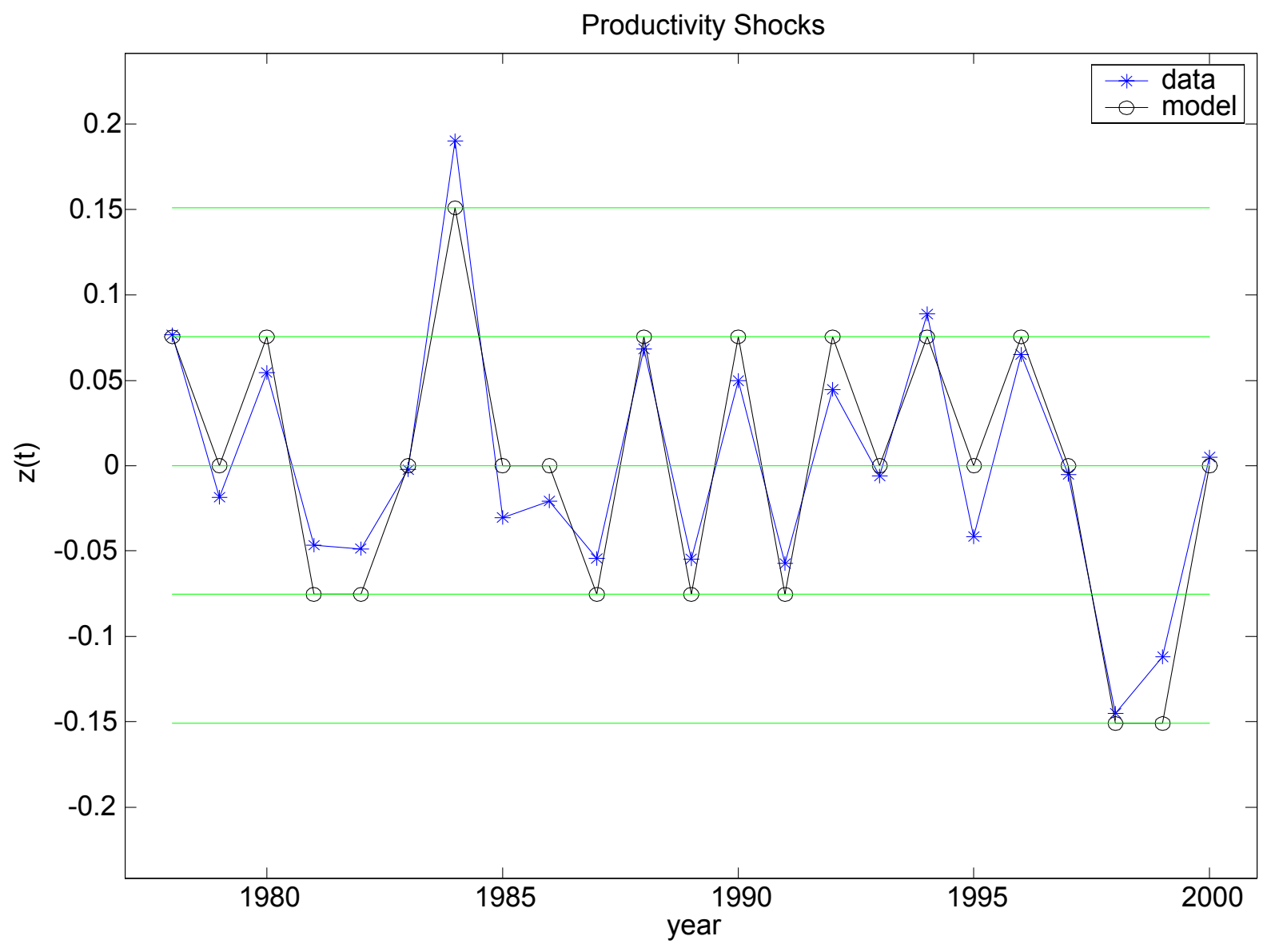


Figure 2: Biomass Stock

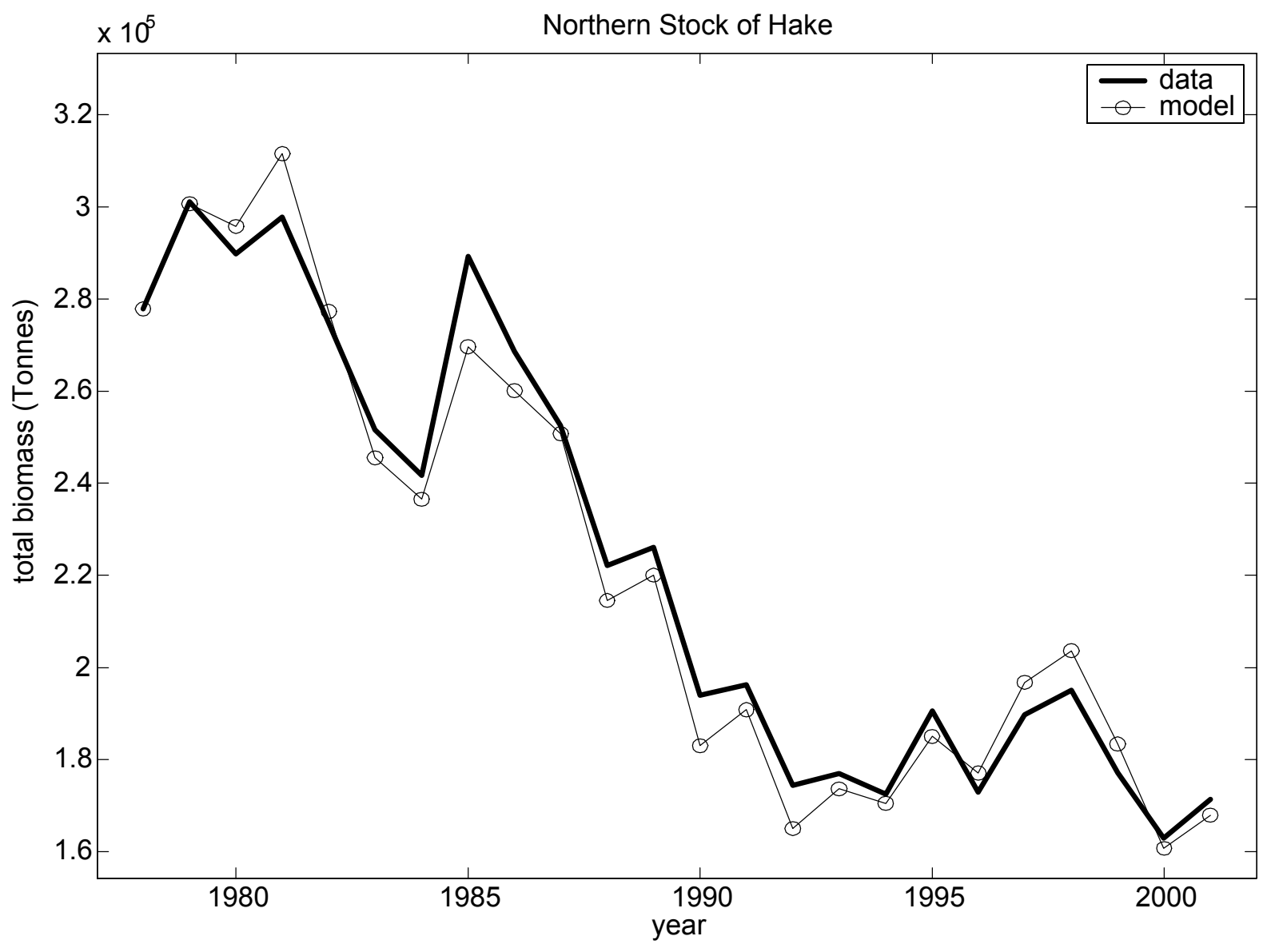


Figure 3: CFP vs data:(a) Optimal Stock; (b) Catches
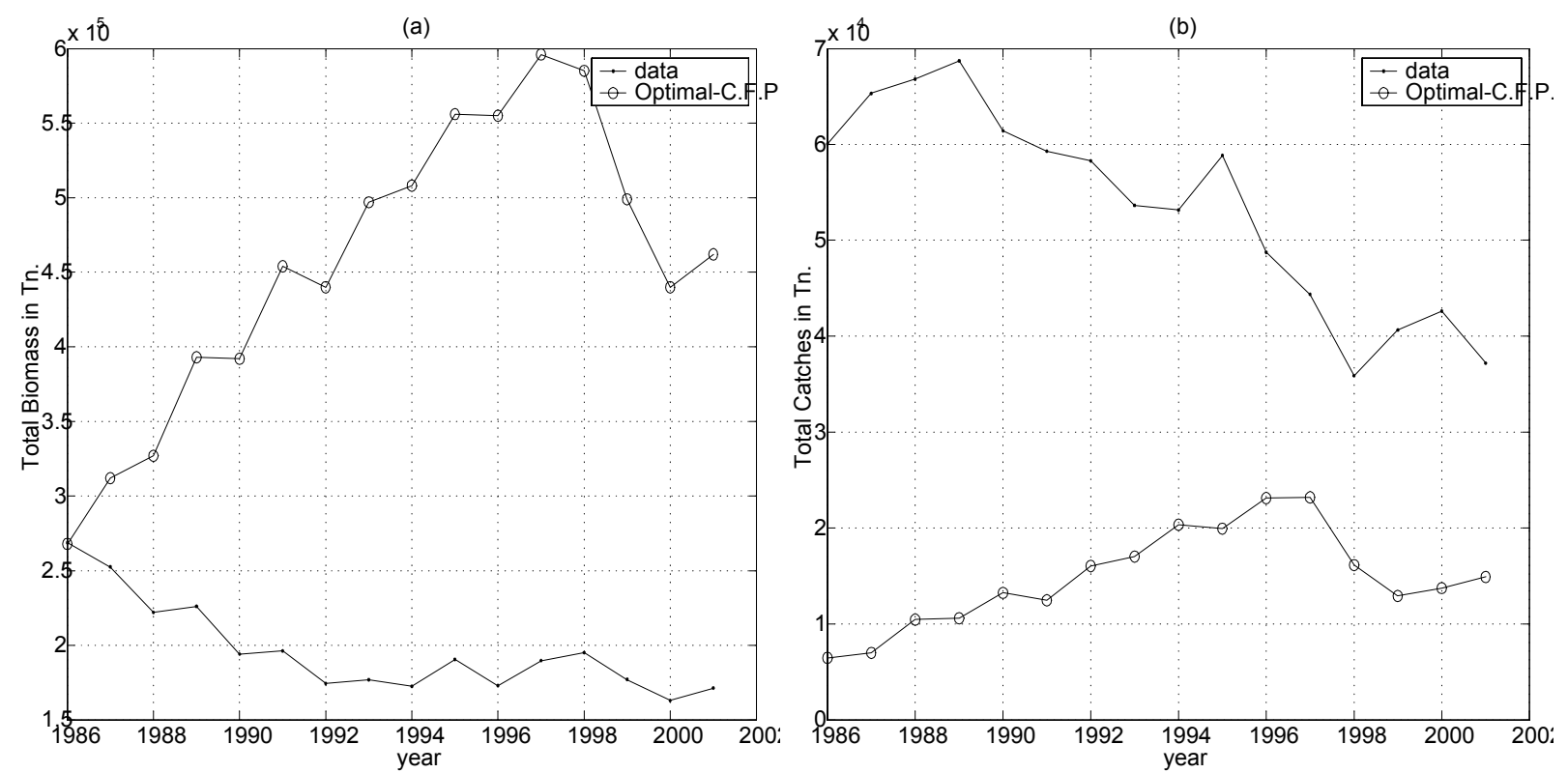
Figure 4: Optimal TAC's. (a) Total; (b) Spain; (c) France; (d) Rest of Union.
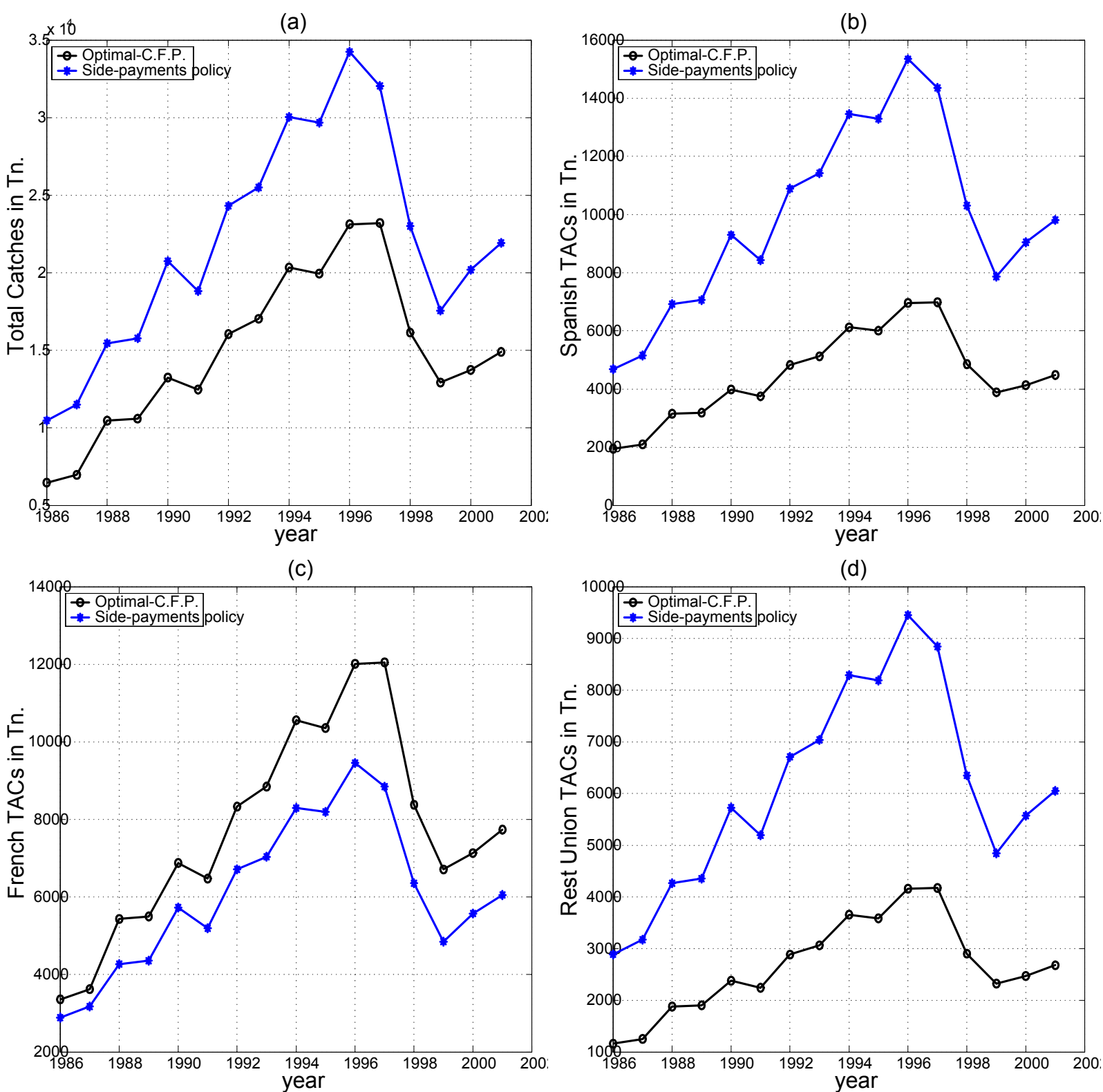
Figure 5: Syde-Payments vs CFP:(a) Optimal Stock; (b) annual increase in profits
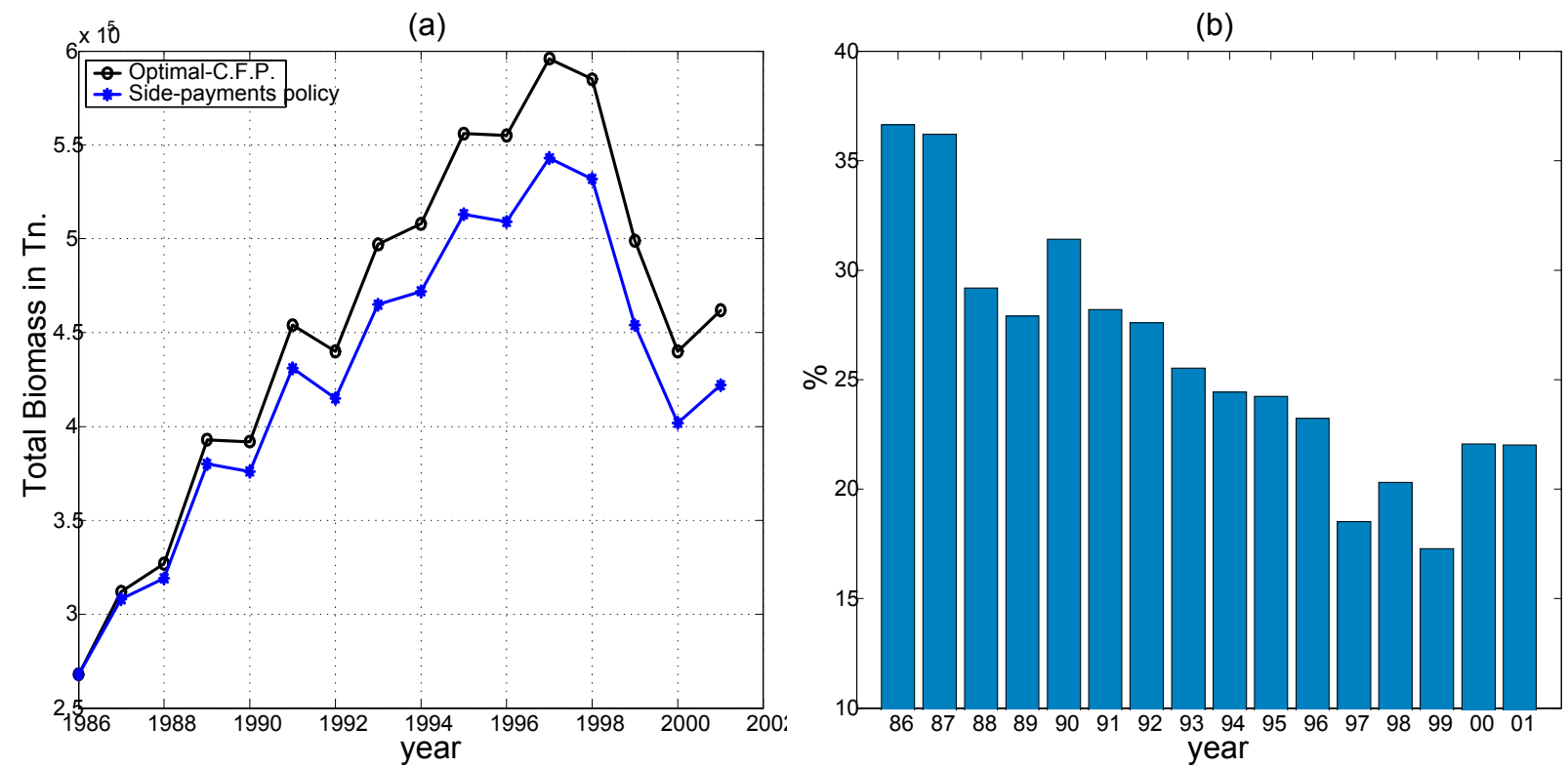
Table 1: Effort and shares for trawl fleets ${ }^{a)}$

\begin{tabular}{lllcc}
\hline \hline & \multicolumn{2}{c}{ Spain } & \multicolumn{2}{c}{ France } \\
\hline \multicolumn{1}{c}{ Year } & Effort $^{b)}$ & Share & Effort $^{b)}$ & Share \\
\hline 1988 & 50.41 & 13.47 & 194.18 & 25.97 \\
1989 & 43.75 & 11.40 & 152.12 & 29.79 \\
1990 & 47.43 & 10.85 & 171.50 & 30.82 \\
\hline Average & 47.20 & 11.93 & 172.60 & 28.82 \\
\hline \hline
\end{tabular}

a) Drawn up from data in Table 7 in Appendix A.2

b) Ships of $100 \mathrm{HP}$ fishing 365 days 
Table 2: Calibrated Parameters

\begin{tabular}{|c|r|l|}
\hline Parameter & & Data \\
\hline$A$ & 12.851905 & Northern Stock of Hake, 1978-2001. \\
$\alpha$ & 0.8095038 & Northern Stock of Hake, 1978-2001. \\
$\phi$ & -0.11741 & Northern Stock of Hake, 1978-2001. \\
$z$ and $\pi$ & 0.91950 & c.p.u.e. of Spanish (La Coruña) and French (RESSGASC) Trawls. \\
$\theta_{f r}$ & see text & Total catches in the Northern Stock of Hake, 1978-2001. \\
$\lambda$ & 0.49000 & French effort in areas VII and VIII, 1988-1990. \\
$\beta$ & 0.00618 & French catches in areas VII and VIII, 1988-1990. \\
\hline Parameter & 0.95000 & interest rate $5 \%$. \\
\hline$\gamma_{f r}$ & 1.2344 & Targets \\
$\gamma_{s p}$ & -0.1266 & French TAC, $s_{f r}=0.30100$. \\
$\gamma_{r u}$ & -0.1078 & Other Countries TACs, $s_{r u}=1-s_{f r}-s_{s p}$. \\
$\omega$ & 439.8682 & Fischler proposal criteria, $X=450,000$. \\
\hline
\end{tabular}


Table 3: Observed and Optimal C.F.P

\begin{tabular}{|l|r|r|}
\hline & Data & Optimal C.F.P. \\
\hline$\sum_{t=1987}^{2001} Y_{t}$ & 854,991 & 237,597 \\
$X_{2001}$ & 171,353 & 462,000 \\
$\sum_{t=1987}^{2001} \beta^{t-16} \Pi_{t}$ & & 111,698 \\
\hline \hline
\end{tabular}


Table 4: Optimal shares with side $\operatorname{payments}\left(\gamma_{i}=1 / 3\right)$

\begin{tabular}{|c|c|c|}
\hline shares & & \\
\hline$s_{f r}^{*}$ & 0.2853 & $\theta_{f r}=0.4900$ \\
$s_{s p}^{*}$ & 0.4294 & $\theta_{s p}=0.5329$ \\
$s_{r u}^{*}$ & 0.2853 & $\theta_{r u}=0.4900$ \\
\hline
\end{tabular}


Table 5: Side-Payments vs. Optimal C.F.P.

\begin{tabular}{|l|r|r|}
\hline & Optimal C.F.P. & Side-payments \\
\hline Catches and Stock & & \\
$\sum_{t=1987}^{2001} Y_{t}$ & 237,597 & 351,282 \\
$X_{2001}$ & 462,000 & 422,000 \\
Profits & & \\
$\sum_{t=1987}^{2001} \beta^{t-16} \pi_{t}^{f r}$ & 49,514 & 42,660 \\
$\sum_{t=1987}^{2001} \beta^{t-16} \pi_{t}^{s p}$ & 37,534 & 54,956 \\
$\sum_{t=1987}^{2001} \beta^{t-16} \pi_{t}^{r u}$ & 24,650 & 42,660 \\
$\sum_{t=1987}^{2001} \beta^{t-16} \Pi_{t}$ & 111,698 & 140,276 \\
\hline
\end{tabular}


Table 6: Stock and Catches Data (Tonnes). 1978-2001

\begin{tabular}{ccccccccc}
\hline Year & 1978 & 1979 & 1980 & 1981 & 1982 & 1983 & 1984 & 1985 \\
\hline Stock & 277,849 & 301,131 & 289,775 & 297,869 & 274,870 & 251,573 & 241,759 & 289,182 \\
Catches & 52,908 & 53,799 & 60,459 & 56,264 & 58,057 & 60,128 & 65,149 & 59,939 \\
\hline Year & 1986 & 1987 & 1988 & 1989 & 1990 & 1991 & 1992 & 1993 \\
\hline Stock & 268,652 & 252,517 & 222,101 & 226,086 & 193,996 & 196,294 & 174,406 & 176,920 \\
Catches & 60,053 & 65,320 & 66,818 & 68,781 & 61,410 & 59,286 & 58,290 & 53,637 \\
\hline Year & 1994 & 1995 & 1996 & 1997 & 1998 & 1999 & 2000 & 2001 \\
\hline Stock & 172,519 & 190,523 & 172,909 & 189,652 & 195,118 & 177,133 & 162,990 & 171.353 \\
Catches & 53,140 & 58,862 & 48,759 & 44,357 & 35,877 & 40,648 & 42,624 & 37,192 \\
\hline Source: Report ICES CM 2003/ACFM:01. From Table 16, page 78. & & &
\end{tabular}


Table 7: Data from trawler fleets

\begin{tabular}{rccrc}
\hline & \multicolumn{2}{c}{ Spain } & \multicolumn{2}{c}{ France } \\
\hline Year & c.p.u.e $^{a)}$ & Captures $^{b)}$ & c.p.u.e. $^{c)}$ & Captures $^{d)}$ \\
\hline 1988 & 178.49 & 8998 & 89.35 & 17350 \\
1989 & 179.22 & 7841 & 128.77 & 20490 \\
1990 & 140.53 & 6665 & 110.38 & 18929 \\
\hline
\end{tabular}

a) Coruña trawler fleet. Tn./year. Data from Table 3.2a in the WGHMM ICES Report CM 2003/ACFM:01. b) Spanish trawler fleet fishing in area VII. Tn. Data from Instituto Oceanogáfico de Vigo. c) FR-RESSGASC trawler fleet. Tn./year. Data from Table 3.2c in the WGHMM ICES Report CM 2003/ACFM:01. d) French trawler fleet fishing in area VIII. Tn. Data from Instituto Oceanogáfico de Vigo. 
Table 8: Data from all French fleets fishing in VII and VIII

\begin{tabular}{cccc}
\hline Year & Captures $^{a)}$ & Share $^{b)}$ & Effort $^{c)}$ \\
\hline 1988 & 21895 & 0.327 & 233.45 \\
1989 & 24218 & 0.352 & 257.87 \\
1990 & 21472 & 0.349 & 264.84 \\
\hline
\end{tabular}

Source: Instituto Oceanográfico de Vigo

a) Tonnes; $\left.{ }^{b}\right) \%$ of total stock; ${ }^{c)}$ Ships fishing 365 days 
Table 9: Estimations for Dynamic Resource Equation

\begin{tabular}{|c|c|c|c|c|}
\hline & Estimation & $t$-statistics & $\mathbf{R}^{2}$ & $F$-statistics \\
\hline \multicolumn{5}{|c|}{ Cushing Funtion $F\left(X_{t}\right)=A X_{t}^{\alpha}$} \\
\hline \multicolumn{2}{|c|}{$\mathbf{M S Y}=51,444$} & $\mathbf{X}_{M S Y}=218,610$ & \multicolumn{2}{|c|}{$\mathbf{M C C}=662,932$} \\
\hline$A$ & 12.851905 & $2.737856^{*}$ & 0.845 & 114.128 \\
\hline$\alpha$ & 0.80950384 & $10.683081^{*}$ & & \\
\hline \multicolumn{5}{|c|}{ " Ricker Function $F\left(X_{t}\right)=X_{t} e^{r\left(1-X_{t} / K\right)}$} \\
\hline \multicolumn{2}{|c|}{$\mathbf{M S Y}=52,543$} & $\mathbf{X}_{M S Y}=335,353$ & \multicolumn{2}{|c|}{$\mathrm{MCC}=475,145$} \\
\hline$r$ & 0.39865537 & $5.165175^{*}$ & 0.230 & $6.287^{*}$ \\
\hline$K$ & 475144.54 & $2.875829^{*}$ & & \\
\hline \multicolumn{5}{|c|}{ "Logistic Function $F\left(X_{t}\right)=r X_{t}\left(1-\frac{X_{t}}{K}\right)+X_{t}$} \\
\hline \multicolumn{2}{|c|}{$\mathbf{M S Y}=53,478$} & $\mathbf{X}_{M S Y}=226,656$ & \multicolumn{2}{|c|}{$\mathbf{M C C}=453,312$} \\
\hline$r$ & 0.47188926 & $4.846857^{*}$ & 0.225 & $6.082^{*}$ \\
\hline$K$ & 453312.68 & $2.8279229 *$ & & \\
\hline \multicolumn{5}{|c|}{ Logistic with MVP $F\left(X_{t}\right)=r X_{t}\left(\frac{X_{t}}{k_{0}}-1\right)\left(1-\frac{X_{t}}{K}\right)+X_{t}$} \\
\hline \multicolumn{2}{|c|}{$\mathrm{MSY}=4.31 \mathrm{E} 15$} & $\mathbf{X}_{M S Y}=20142,185$ & \multicolumn{2}{|c|}{$\mathbf{M C C}=30213,277$} \\
\hline$r$ & -0.47369208 & 0.663937 & 0.225 & 2.896 \\
\hline$K$ & 0213,277 & 0.002571 & & \\
\hline$K_{0}$ & -0.014829952 & -0.002585 & & \\
\hline \multicolumn{5}{|c|}{ בGompertz Function $F\left(X_{t}\right)=r X_{t} \ln \left(\frac{K}{X_{t}}\right)+X_{t}$} \\
\hline \multicolumn{2}{|c|}{$\mathbf{M S Y}=52,356$} & $\mathbf{X}_{M S Y}=221,565$ & $\mathbf{M C C}=602$, & \\
\hline$r$ & 0.23630267 & $2.471978^{*}$ & 0.225 & $6.111^{*}$ \\
\hline$K$ & 602277.14 & 0.19254299 & & \\
\hline
\end{tabular}

